\title{
Case Report: Nodular colloid degeneration of the skin [version
}

\section{1; peer review: 1 approved, 1 approved with reservations]}

\author{
Nasim Niknezhad1 ${ }^{1}$ Farahnaz Bidari-Zerehpoosh², Nakisa Niknejad³, \\ Nikoo Mozafari (iD)
}

${ }^{1}$ Skin Research Center, Shahid Beheshti University of Medical Sciences, Tehran, Iran

2Department of Pathology, Shahid Beheshti University of Medical Sciences, Tehran, Iran

${ }^{3}$ Department of Pathology, Cancer Institute, Imam Khomeini Hospital Complex, Tehran University of Medical Sciences, Tehran, Iran

V1 First published: 25 Oct $2019,8: 1798$

https://doi.org/10.12688/f1000research.19850.1

Latest published: 25 Oct 2019, 8:1798

https://doi.org/10.12688/f1000research.19850.1

\section{Abstract}

In this report, we described a 58-year-old man, presenting with multiple plaques and nodules over the nose and forehead resembling sarcoidosis or lepromatous leprosy. The histologic study revealed deposition of the mass of amorphous, eosinophilic-cleaved, colloid materials in the papillary dermis and deep dermis. The periodic acidSchiff (PAS) stain was positive, whereas the Congo red stain was negative. Based on the clinical and pathologic findings, the patient was diagnosed with nodular colloid degeneration(NCD). To treat the patient, lesions were flattened using a Co2 laser. The patient did not return for follow-up. NCD is a rare disease, with only 12 cases having been previously reported. Here, we present a case of NCD that occurred on the face and discuss the topic of how to discriminate between NCD and other similar entities, emphasizing that nodular colloid degeneration should be considered in the differential diagnosis of asymptomatic facial plaques and nodules.

Keywords

Nodular colloid degeneration, Colloid milium, Nodular amyloidosis

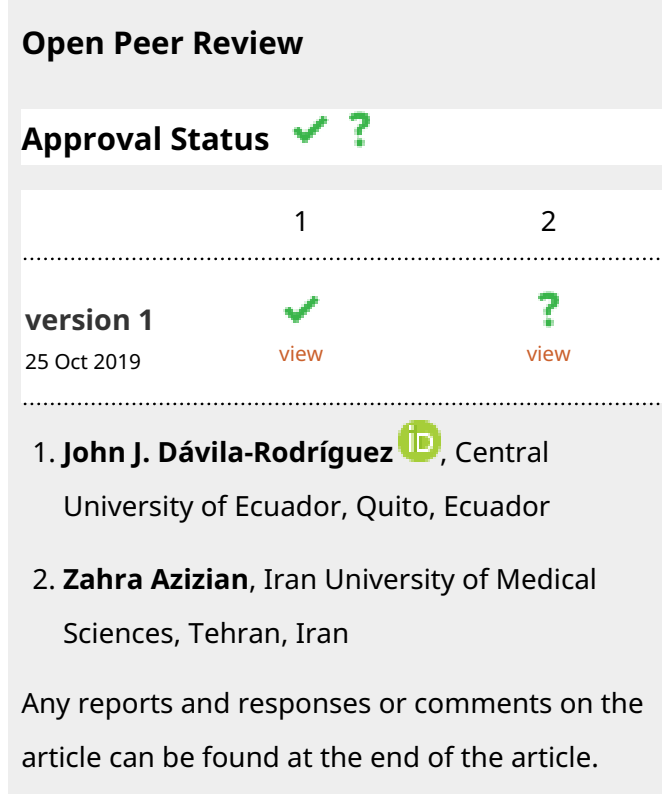

Corresponding author: Nikoo Mozafari (Nikoo_MD@yahoo.com)

Author roles: Niknezhad N: Writing - Original Draft Preparation, Writing - Review \& Editing; Bidari-Zerehpoosh F: Writing - Original Draft Preparation; Niknejad N: Writing - Original Draft Preparation, Writing - Review \& Editing; Mozafari N: Writing - Original Draft Preparation, Writing - Review \& Editing

Competing interests: No competing interests were disclosed.

Grant information: The author(s) declared that no grants were involved in supporting this work.

Copyright: ( 2019 Niknezhad $\mathrm{N}$ et al. This is an open access article distributed under the terms of the Creative Commons Attribution License, which permits unrestricted use, distribution, and reproduction in any medium, provided the original work is properly cited.

How to cite this article: Niknezhad N, Bidari-Zerehpoosh F, Niknejad N and Mozafari N. Case Report: Nodular colloid degeneration of the skin [version 1; peer review: 1 approved, 1 approved with reservations] F1000Research 2019, 8:1798

https://doi.org/10.12688/f1000research.19850.1

First published: 25 Oct 2019, 8:1798 https://doi.org/10.12688/f1000research.19850.1 


\section{Introduction}

Nodular colloid degeneration (NCD), also named paracolloid, is a rare subtype of colloid deposition disorders. It presents as a single or multiple soft to rubbery nodules or plaques usually on chronically sun-exposed skin. Histologically, there are masses of amorphous, eosinophilic material expanding the papillary dermis and extending into the deep dermis ${ }^{1}$. Nodular colloid degeneration is a rare disease. Only 12 cases have been previously reported in the literature. Here, we present a case of NCD that occurred on the face and discuss the topic of how to discriminate between NCD and other similar entities such as nodular amyloidosis.

\section{Case presentation}

A previously healthy 58-year-old farmer from Hamedan province, Iran, presented to the dermatology clinic with a three year history of multiple papular and nodular lesions on his face. The lesions had been gradually enlarging during last six months. An examination of the skin carried out by a dermatologist revealed multiple skin-colored to yellow papules and nodules of different sizes (10-25mm) located on the forehead, cheeks, and nares (Figure 1 and Figure 2). The nodules were painless and mobile, they were rubbery-soft in consistency and were attached to the overlying skin. Findings of the systemic physical examination were otherwise unremarkable.

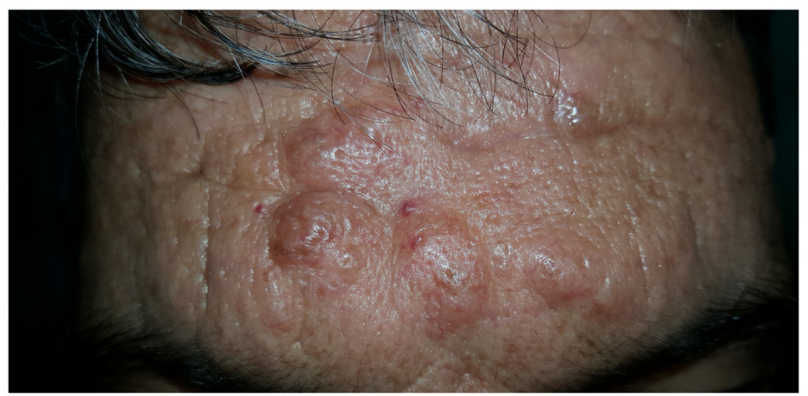

Figure 1. Yellowish papules and nodules of different sizes located on the forehead.

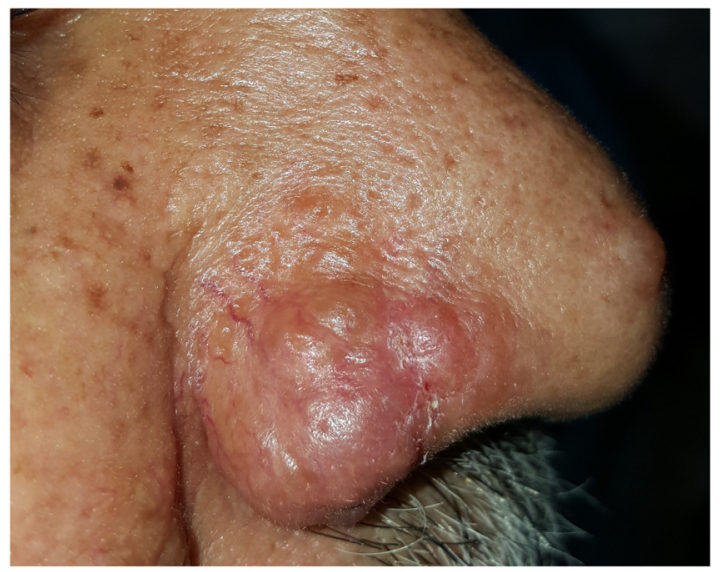

Figure 2. A lobulated plaque consisting of some yellowish nodules on the nose.
After local anesthesia using $2-3 \mathrm{ml}$ of intralesional lidocaine (2\%), an excisional biopsy was obtained from forehead lesions. The specimen was put in formalin and was sent to the lab for routine hematoxylin-eosin stain and special stains (periodic acid-Schiff (PAS) staining, crystal-violet and Congo red staining).

Histopathologic examination revealed hyperkeratosis, flattened epidermis, and amorphous eosinophilic material deposits in the upper dermis, which were separated from the epidermis by a Grenz zone of collagen fibers and extended into the deep dermis. The hair follicles and sebaceous glands were well preserved. There were some irregular fissures and clefts in the hyaline material dividing this material into smaller islands. Scattered nuclei of fibroblast were aligned along the line of fissuring (Figure 3).

The special stains revealed positive reactivity of materials with periodic acid-Schiff (PAS) staining but negative reactivity with crystal-violet and Congo red staining. According to clinical and histopathological findings, nodular lesions on sunexposed areas with colloid material deposition in the dermis, a diagnosis of nodular colloid degeneration was made.

For treatment, forehead lesions were excised and for the lesions on the nose, resurfacing using a Co2 laser (Jeisys Medical Korea) was applied with a frequency of $50 \mathrm{kHz}$ and pulse duration of $500 \mu$ s. Unfortunately, the patient did not return for follow-up and we could not obtain data on treatment efficacy, cosmetic results or recurrence.

\section{Discussion}

Colloid milium and colloid degeneration are rare degenerative cutaneous disorders, with at least four distinct clinicopathological variants. The four variants of this disease are as follows: adult

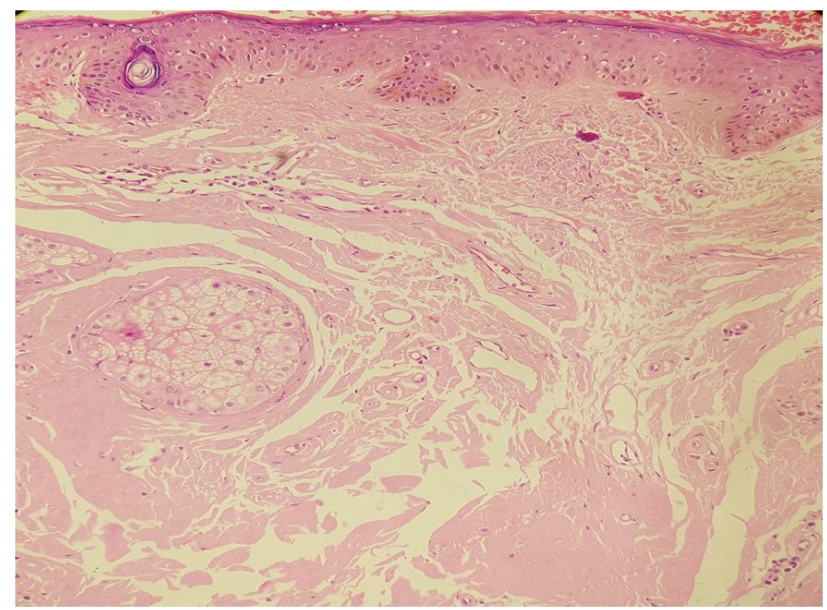

Figure 3. The biopsy specimen from the forehead area showing hyperkeratosis and mild acanthosis in the epidermis and deposition of amorphous colloid materials in the dermis, expanding to the reticular dermis and extending to the deep dermis. The amorphous colloid material shows numerous irregular clefts. Scattered nuclei of fibroblasts are observed in the colloid material (haemotoxylin and eosin staining, $\times 40$ ). 
colloid milium, juvenile colloid milium, pigmented colloid milium, and nodular colloid degeneration (para colloid) ${ }^{2}$.

In both the adult and juvenile forms, numerous yellow-brown, semitranslucent dome-shaped papules are developed in areas of chronic sun exposure; for example, the cheeks, ears, neck, and dorsum of the hands. In pigmented colloid milium, gray to black grouped or confluent papules are present on the face, following the excessive use of topical hydroquinone for skin bleaching ${ }^{2}$.

NCD clinically presents with solitary or multiple asymptomatic nodules or plaque-like lesions usually in chronically sun-exposed areas, particularly the face. The lesions have been rarely reported on sun protected areas such as penile skin ${ }^{3}$. Although the exact etiologic role of chronic sun exposure remains uncertain, it is suggested that photo-induced damage to dermal elastic fibers, as in solar elastosis, produce the colloid ${ }^{4}$.

Clinically, the differential diagnosis of NCD includes nodular amyloidosis, nodular mastocytosis, nodular histiocytosis, steatocystoma multiplex, sarcoidosis, lepromatous leprosy, leishmaniasis, cutaneous lymphoma, and pseudolymphoma ${ }^{1,2}$. A histopathologic workup is a helpful tool in establishing the appropriate diagnosis. Upon histopathologic examination, an amorphous eosinophilic material with small fissure and clefts is observed in the dermis, separated from the epidermis by a Grenz zone of narrow collagen tissue ${ }^{2,5}$.

Histologically, NCD must be distinguished from lipoid proteinosis, different types of colloid milium, and amyloidosis. In cutaneous lesions of lipoid proteinosis, there are masses of amorphous or laminated hyaline-like PAS-positive deposits in the dermis that have the striking perivascular pattern and also can surround the eccrine glands as well as the hair follicles and sebaceous glands ${ }^{6}$.

In juvenile colloid milium, amorphous eosinophilic deposits are found in the dermis next to basal layer without Grenz zone. In adult colloid milium, nodules of homogenous eosinophilic colloid material expand the papillary dermis and extend into the mid dermis. Fissures and clefts divide this material into smaller islands and evidence of solar elastosis are commonly seen beneath the nodules. The Grenz zone is often present in the dermis. A pigmented colloid milium is similar to adult colloid milium but contains an area of yellow-brown islands of colloid material in the upper dermis. Nodular colloid degeneration is distinguished from adult colloid milium and juvenile colloid milium by more deeply extended and less conspicuous clefting of amorphous materials within the dermis ${ }^{2,7}$.

The main histologic differential diagnosis of nodular colloid degeneration includes nodular amyloidosis. In nodular amyloidosis, there are large masses of amyloid in the dermis and subcutaneous fat, accentuate around deep vascular channels, adnexal structures, and infiltrate blood vessel walls ${ }^{8}$. Infiltration of plasma cells are usually present in and around the amyloid deposition?

There is a considerable resemblance between colloid milium and amyloidosis, as both may stain positively for Congo red, PAS and crystal violet, and produce fluorescence with Thioflavin-T. In contrast to colloid, amyloid reacts with Pagoda-red and other cotton dyes ${ }^{8}$. Moreover, infiltrate of plasma cells and positive immunostaining for light chain deposition can aid in the differentiation of amyloidosis from $\mathrm{NCD}^{8}$.

To improve the appearance of the lesions, cryotherapy, dermabrasion, erbium:YAG or carbon dioxide laser resurfacing have been reported as effective methods, although lesions may recur. Considering the pathogenesis of $\mathrm{NCD}$, sun protection can be effective in preventing $\mathrm{NCD}^{2}$. In this case, we used excision and $\mathrm{Co} 2$ laser resurfacing to flatten the lesions. Unfortunately, the patient did not return for follow-up and we could not obtain data on treatment efficacy, cosmetic results or recurrence.

In summary, we encountered a rare case of nodular colloid degeneration arising on the face, which was diagnosed by histopathological examination. Although it is rare, the clinical diagnosis of nodular colloid degeneration should be considered in differential diagnosis of any cases presenting with facial nodules.

\section{Data availability}

All data underlying the results are available as part of the article and no additional source data are required.

\section{Consent}

Written informed consent for publication of their clinical details and clinical images was obtained from the patient.
1. Chu H, Kim HJ, Lee MG: Xanthoma-like multiple yellowish nodular colloid degeneration on the face and scalp. J Eur Acad Dermatol Venereol. 2017; 31(4): e195-e196.

PubMed Abstract | Publisher Full Text

2. Choi WJ, Kim BC, Park EJ, et al:: Nodular colloid degeneration. Am J Dermatopathol. 2011; 33(4): 388-391. Dermatopathol. 2011; 33(4): 388-391.
PubMed Abstract | Publisher Full Text

3. Preston PW, Orpin SD, Muc R, et al:: Penile colloid degeneration. Clin Exp Dermatol. 2006; 31(5): 674-676. PubMed Abstract | Publisher Full Text

4. Hashimoto K, Black M: Colloid milium: a final degeneration product of actinic elastoid. J Cutan Pathol. 1985; 12(2): 147-156. PubMed Abstract | Publisher Full Text
5. Patterson JW, Wilkin JK, Schatzki PF: Nodular colloid degeneration: distinctive histochemical and ultrastructural features. Cutis. 1985; 36(4): 355-358.

PubMed Abstract

6. McGrath JA: Lipoid proteinosis. Handb Clin Neurol. 2015; 132 : 317-322.

PubMed Abstract | Publisher Full Text

7. Patterson J: Weedon's Skin Pathology. 4th ed:Elsevier. 2016. Reference Source

8. Lai KW, Lambert E, Coleman S, et al:: Nodular amyloidosis: differentiation from colloid milium by electron microscopy. Am J Dermatopathol. 2009; 31(5): 472-474.

PubMed Abstract | Publisher Full Text 


\section{Open Peer Review}

\section{Current Peer Review Status:}

\section{Version 1}

Reviewer Report 18 November 2019

https://doi.org/10.5256/f1000research.21778.r55748

(C) 2019 Azizian Z. This is an open access peer review report distributed under the terms of the Creative Commons Attribution License, which permits unrestricted use, distribution, and reproduction in any medium, provided the original work is properly cited.

\section{Zahra Azizian}

Iran University of Medical Sciences, Tehran, Iran

1. Please mention other case reports of nodullar colloid millium.

2. Explain about the difference of your case with other case reports of this disease

3. Explain about the method of ruling out other differential diagnosis?

4. Please mention the period of time that the patient was free of disease.

5. Explain about the common age and gender of this disease. Is your case different in any point of view from other cases of this disease?

6. More up to date references are required.

Is the background of the case's history and progression described in sufficient detail? Yes

Are enough details provided of any physical examination and diagnostic tests, treatment given and outcomes?

Partly

Is sufficient discussion included of the importance of the findings and their relevance to future understanding of disease processes, diagnosis or treatment?

Partly

Is the case presented with sufficient detail to be useful for other practitioners? Partly 
Competing Interests: No competing interests were disclosed.

Reviewer Expertise: Dermatology

I confirm that I have read this submission and believe that I have an appropriate level of expertise to confirm that it is of an acceptable scientific standard, however I have significant reservations, as outlined above.

Reviewer Report 08 November 2019

https://doi.org/10.5256/f1000research.21778.r56166

(C) 2019 Dávila-Rodríguez J. This is an open access peer review report distributed under the terms of the Creative Commons Attribution License, which permits unrestricted use, distribution, and reproduction in any medium, provided the original work is properly cited.

\section{John J. Dávila-Rodríguez}

Department of Dermatology, Central University of Ecuador, Quito, Ecuador

The authors describe a very interesting case of nodular type milium colloid associated to UV radiation. It affirms the association demonstrated in several studies. The authors have made an appropriate review of the topic. I consider that after some minimum suggested changes the article should be indexed.

Please make the following corrections in these sections:

\section{Abstract}

P.1: Please change the text "deposition of the mass..." to deposition of an amorphous, eosinophilic-cleaved, colloid material.

\section{Case Presentation}

P.2: The text "After local anesthesia using $2-3 \mathrm{ml}$ of intralesional lidocaine (2\%), an excisional biopsy was obtained from forehead lesions. The specimen was put in formalin and was sent to the lab for routine hematoxylin-eosin stain and special stains (periodic acid-Schiff (PAS) staining, crystal-violet and Congo red staining) " is not relevant. Please remove it.

\section{P.3: Please delete the text "of collagen fibers".}

P.5: Please indicate the $\mathrm{CO}_{2}$ laser fluences used.

Figure 3: Please delete the text "The biopsy specimen from the forehead area showing".

Dear authors, it would be interesting to create a comparative table of the 12 cases reported in the literature. It should include possible causes, clinical features, histopathology, treatments performed and evolution of the cases.

Please include the PAS staining photograph. It could be done in the figure 3 or adding a 
new figure.

Please include the following two current references on this topic:

1. Dávila-Rodríguez J, Aguilar K, García L. Colloid milium, an expression of excessive sun exposure in Ecuadorian patients. Int J Dermatol. 2019: 58 (4); e80-e82.

https://doi.org/10.1111/ijd.14384

2. Ghanadan A, Kamyab K, Daneshpajouh M, et al. Nodular colloid degeneration of the skin: report of three cases with review and update. Int Dermatol J. 2014; 5: 36. https://doi.org/10.4103/2229-5178.1445272

With these references please try to broaden the knowledge about the pathophysiology of the disease, for example "UV exposure could cause degeneration of keratinocytes and elastic and collagen fibers with secondary accumulation of protein products and fibroblast secretions".

\section{References}

1. Dávila-Rodríguez J, Aguilar K, García L: Colloid milium, an expression of excessive sun exposure in Ecuadorian patients. International Journal of Dermatology. 2019; 58 (4): E80-E82 Publisher Full Text

2. Ghanadan A, Kamyab-Hesari K, Daneshpajouh M, Balighi K, et al.: Nodular colloid degeneration of the skin: Report of three cases with review and update. Indian Dermatology Online Journal. 2014; 5 (5). Publisher Full Text

Is the background of the case's history and progression described in sufficient detail? Partly

Are enough details provided of any physical examination and diagnostic tests, treatment given and outcomes?

Yes

Is sufficient discussion included of the importance of the findings and their relevance to future understanding of disease processes, diagnosis or treatment? Partly

Is the case presented with sufficient detail to be useful for other practitioners? Partly

Competing Interests: No competing interests were disclosed.

Reviewer Expertise: Dermatology, Melanoma, Laser, Cutaneous Oncology, Dermatologic Surgery, Aesthetic dermatology, Dermoscopy

I confirm that I have read this submission and believe that I have an appropriate level of expertise to confirm that it is of an acceptable scientific standard. 
The benefits of publishing with F1000Research:

- Your article is published within days, with no editorial bias

- You can publish traditional articles, null/negative results, case reports, data notes and more

- The peer review process is transparent and collaborative

- Your article is indexed in PubMed after passing peer review

- Dedicated customer support at every stage

For pre-submission enquiries, contact research@f1000.com 